\title{
Case Report \\ Obstetrical Management of an Extremely Overweight Pregnant Woman (184 kg bw) with Special Attention on Thromboprophylaxis
}

\author{
Boldizsar Horváth, ${ }^{1,2}$ Judit Skrapits, ${ }^{2}$ and József Bódis ${ }^{1}$ \\ ${ }^{1}$ Faculty of Health Sciences, University of Pécs, Vörösmarty ut 3., Pécs 7621, Hungary \\ ${ }^{2}$ Markusovszky Teaching Hospital, Markusovszky u. 3., Szombathely 9700, Hungary \\ Correspondence should be addressed to Boldizsar Horváth; drhorvathboldizsar@gmail.com
}

Received 12 December 2012; Accepted 27 January 2013

Academic Editors: K. Dafopoulos, C. Ficicioglu, B. Piura, and I. M. Usta

Copyright ( 2013 Boldizsar Horváth et al. This is an open access article distributed under the Creative Commons Attribution License, which permits unrestricted use, distribution, and reproduction in any medium, provided the original work is properly cited.

The 27-year-old pregnant woman has been overweight since her childhood. Endocrinological assessments did not confirm hormonal disease. Her pregnancy was without complication. A signs of intrauterine distress were observed and elective caesarean section was performed under heparin protection because of anatomy unsuitable for delivery per vias naturals. The mother's bodyweight was $184 \mathrm{~kg}$. By monitoring the change in $\mathrm{XX}$ activity LMWH treatment (Enoxaparin) initiated with a dose of $120 \mathrm{mg}$ twice daily and then the dose was gradually elevated to $200 \mathrm{mg}$ twice daily thereby achieving the lower range of the desired therapeutic effect. Apart from mild disorder of wound healing, the recovery was free of complication. The patient suffered from thrombophilia (extremely overweight, pregnant, thrombophlebitis under the knee, surgery, and postoperative immobilization). In case of quite extreme bodyweight there is no dosage recommendation or clinical practice for LMWH. Because of the extreme overweight and the therapeutic dose titration test of heparin, monitoring of $\mathrm{fX}$ activity by measurement of inhibition, dosage of heparin other than the recommended (abdominal wall instead of upper arm SC), and the very fluctuating heparin dosage which is well correlating with clinical practice, it is reasonably expected that this case will take interest.

\section{Introduction}

Overweight and obesity have proven to be the most significant health problem of the present time and the future. Data from the WHO have shown that overweight and obesity are the second most important preventable risk factor after smoking [1]. Obesity is known to be harmful to health as obese people more often suffer from diseases that increase premature mortality which is on one hand the consequence of direct effects and on the other hand can be explained by the other diseases that develop [2-4]. As obesity may be associated with many maternal and foetal/neonatal complications, it is advisable that the gynaecologist informs his/her patient of the relevant risks preferably before the obese woman gets pregnant. The higher the patient's BMI (Body Mass Index) is, the greater the probability of complication is [5-14]. In obese pregnant women (BMI $>30 \mathrm{~kg} / \mathrm{m}^{2}$ ) the incidence of gestational diabetes can be even 20 times the value measured in mothers with physiological bodyweight $[3,7,13,14]$. The incidence of hypertension and preeclampsia is 2.221.4 and 9.7 times higher, respectively, compared to women with normal bodyweight. Obesity also significantly increases the risk of thromboembolic diseases [7, 15-19]. The risk of perinatal mortality is 2.5 to 3.4 times higher in overweight and obese pregnant women, respectively, compared to the mothers with physiological bodyweight $[2,4,5,8,18-20]$.

Our case was extremely obese. The value of the socalled grade IV obesity is above 40 based on BMI, and our patient's bodyweight was $184 \mathrm{~kg}$ equivalent to 59.4! BMI. This overweight may raise medicinal, management, and technical-logistical problems. In our case-due to the lack of experience with the management of such patients-selection of the efficient thromboprophylaxis seemed critical. We could examine and follow the efficiency of heparin therapy adjusted 
TABle 1: Pre-, peri-, and postoperative days the examine and follow the efficiency of heparin therapy by monitoring of anti-Xa activity.

\begin{tabular}{|c|c|c|c|c|c|c|c|c|}
\hline Days & $\begin{array}{l}\text { Sd. } 38 \\
\text { Day } 6 \\
\end{array}$ & $\begin{array}{c}\text { Opus } \\
\text { Day } 1^{*}\end{array}$ & $\begin{array}{c}\text { Opus } \\
\text { Day } 0^{* *}\end{array}$ & $\begin{array}{l}\text { Postop. } \\
\text { Hour } 6\end{array}$ & $\begin{array}{c}\text { Postop. } \\
\text { Day } 2 \\
\end{array}$ & $\begin{array}{c}\text { Puerp. } \\
\text { Day } 6\end{array}$ & $\begin{array}{c}\text { Puerp. } \\
\text { Day } 32^{* * *}\end{array}$ & $\begin{array}{l}\text { Puerp. } \\
\text { Day } 40\end{array}$ \\
\hline MWH (Clexane) mg & $2 \times 160$ & $2 \times 180$ & $2 \times 200$ & $2 \times 200$ & $2 \times 200$ & $2 \times 200$ & $2 \times 220$ & $2 \times 200$ \\
\hline Heparin level IU/mL aXf. ${ }^{* * * *}$ & 0.01 & 0.45 & 0.45 & 0.45 & 0.55 & 0.55 & 0.20 & 0.60 \\
\hline Comment & Hospital admission & \multicolumn{3}{|c|}{ Perioperative period } & Self-administer bid & Infection & $\begin{array}{c}\text { Faulty heparin } \\
\text { measurement }\end{array}$ & Recovery \\
\hline
\end{tabular}

${ }^{*}$ Due to the extremely robust abdominal wall the patient was administered heparin into the subcutaneous region of her shoulder for better absorption.

** At time of performing caesarean section.

${ }^{* * *}$ The patient self-administered heparin later (she fell asleep) and measurement occurred $2 \mathrm{~h}$ after administer LMWH.

${ }^{* * * *}$ The target was to achieve at least 0.5 anti-Xa activity four hours after injection.

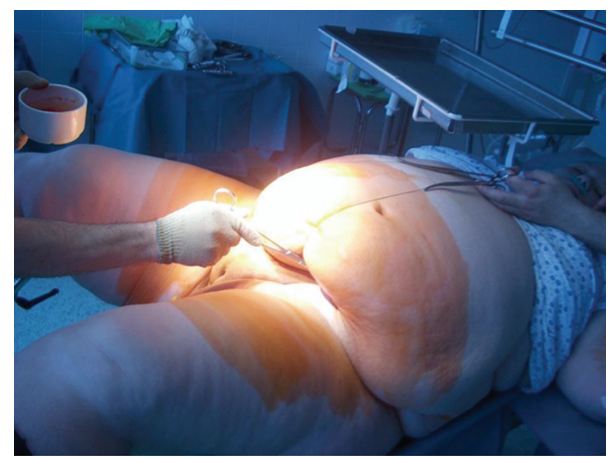

FIGURE 1: Preoperative preparation release of hanging abdomen to open the abdomen.

to bodyweight in an extreme situation (as far as we know there is a very few healthcare providers that can deal with such situation); this is why we believe it is important to report our experiences.

\section{Case Study}

G.O. a 27-year-old pregnant woman has been overweight since her childhood. Multiple endocrinological assessments did not confirm hormonal disease. She has suffered from moderate bronchial asthma since her childhood but she did not have any other diseases. She did not have metabolic syndrome since the laboratory tests performed one year before she became pregnant did not indicate this (lack of insulin resistance, se. Cholesterol $5.3 \mathrm{mmol} / \mathrm{L}$ (ref. 3.9-5.2), se. HDL $2.0 \mathrm{mmol} / \mathrm{L}(0.9-)$, se LDL $2.5 \mathrm{mmol} / \mathrm{L}$ (0.1-3.4), se. Triglyceride $1.7 \mathrm{mmol} / \mathrm{L}(0.5-2.3))$. Her cycles were regular; she became pregnant in the 4 th cycle without contraception. At this time her bodyweight was approximately $174 \mathrm{~kg}$; uxor was $62 \mathrm{~kg}$. Her data showed that the pregnancy progressed normally; oral glucose tolerance test performed at week 27 confirmed normal carbohydrate metabolism (after administration of $75 \mathrm{~g}$ carbohydrate her blood glucose level was 5.0$7.8-6.4 \mathrm{mmol} / \mathrm{L})$.

The pregnant woman treated in another institute was referred to our ward by her public health nurse due to hypertension near the end of pregnancy. Her blood pressure was $150 / 100 \mathrm{~mm} \mathrm{Hg}$ at admission but no proteinuria was found. Untreated thrombophlebitis developing within few days below her right knee was found; additionally we recorded normal pregnancy. In addition to antihypertensive treatment and administration of diosmin (Detralex) and $\alpha$-amino-benzyl-penicillin (Ampicillin), we applied heparin therapy. Based on thromboembolic risk assessment we categorized our patient into "very high risk group" when 1 to $1.5 \mathrm{mg} / \mathrm{kg}$ bw low molecular weight heparin (LMWH) twice daily is recommended. At this time our patient's bodyweight was $184 \mathrm{~kg}$. We did not have experience with doses to be administered in case of such high bodyweight and we did not find relevant data even in the literature. We prescribed $120 \mathrm{mg}$ Enoxaparin Sodium (Clexane) bid and monitoring of heparin therapy (Siemens Berichrom Heparin Calculator). The target was to achieve at least 0.5 anti-Xa activity four hours after injection [21-24]. After gradual increase of Clexane dose $(2 \times$ $160,2 \times 180$, and $2 \times 200 \mathrm{mg}$ /day!), we measured therapeutic level on the fourth day (Table 1). Due to the extremely robust abdominal wall, the patient was administered heparin into the subcutaneous region of her shoulder for better absorption. After few days observation elective caesarean section was applied because of symptoms of mild intrauterine distress and the anatomy unsuitable for delivery through natural way (cervix cannot be found either digitally or with exploration). Surgery was performed under spinal anaesthesia according to Misgav-Ladach method in agreement with the patient because we found that her abdominal wall is the less thick in the abdominal fold (approx. $8 \mathrm{~cm}$, in whole it was $16 \mathrm{~cm}$ at the level of linea alba inferior) (Figure 1). At the beginning of surgery the assistant standing at the head of the patient kept the pendulum abdomen above the planned surgical site and maintained its position by equipment during surgery by placement of three stitches-forming a bow (Figure 1). During the uneventful surgery a healthy female neonate was born with $2950 \mathrm{~g}$ bodyweight and with APGAR value of 8-10. Administration of $200 \mathrm{mg}$ LMWH bid was discontinued prior to surgery later than recommended by the guidelines $(10 \mathrm{~h})$ and continued earlier 6 hours after surgery and mechanic thromboprophylaxis was also applied. Our patient who was very cooperative was mobilized 20 hours after surgery with no haemorrhagic complications observed. Despite perioperative antibiotic prophylaxis, our patient got fever on day 6 after surgery and infection of the abdominal wound was observed in the adipose layer. Wound toilet was applied twice daily (Figure 2). On day 12 of patient 


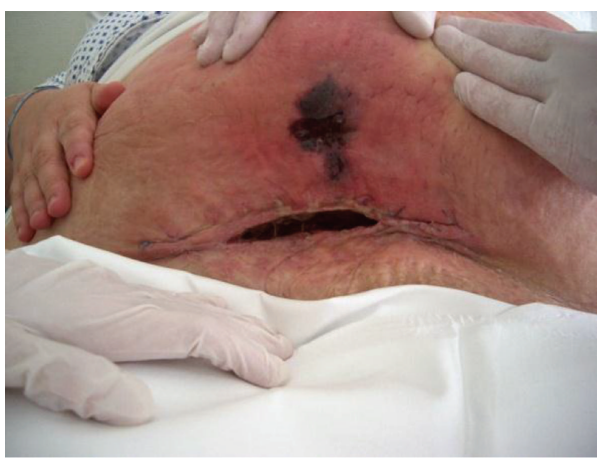

(a)

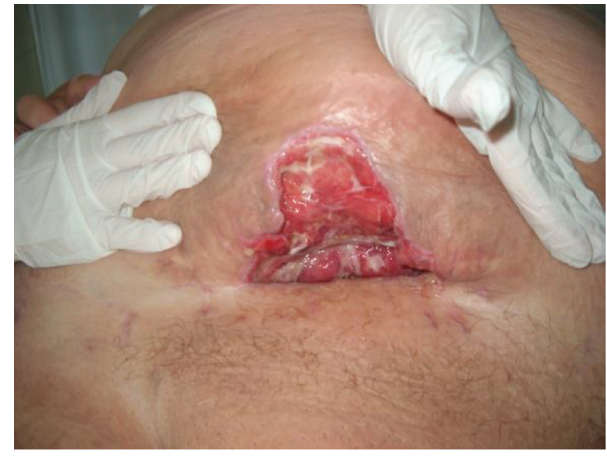

(b)

FIGURE 2: Wound healing on days 10 and 21 after surgery.

care she was discharged and instructed to return for wound treatment every day and self-administer $2 \times 200 \mathrm{mg}$ heparin bid, and weekly measurement of heparin level was required. Anti-fX activity confirmed therapeutic level while on day 32 after surgery the value was only 0.2 suddenly. It turned out that patient self-administered heparin later (she fell asleep) and the usual heparin measurement occurred 2 hours after administration of the drug (Table 1). Wound treatment was applied until week 4 after surgery and heparin treatment was given for 2 months. Week 6 follow-up examination confirmed normal status aside from the extreme bodyweight of the patient $(173 \mathrm{~kg} \mathrm{bw})$.

\section{Discussion}

The thromboembolic disease is a multicausal condition; few components of it could be observed in our case $[2,15$, 16]. Obese patients significantly increase the risk of venous thromboembolic event; moreover, extremely obese people are categorized as "very high risk" patients [25-27]. Relative risk of thromboembolic complications during pregnancy is $1 / 1000-2000$ deliveries, that is, five to fifteen times increase in risk, and the risk is increased with additional 2-3 times after delivery. Caesarean section alone represents approximately 5 times higher risk compared to vaginal delivery. In each case when the patient is in bed rest (during and after surgery) compression stockings and/or prophylactic anticoagulation (primarily low molecular weight heparin) is recommended both for prophylaxis and treatment of thromboembolic diseases (recommendation level "2C") [17, 25-28].

During caesarean section the literature prefers regional anaesthesia to intratracheal narcosis because of the more frequent complications with the latter. Concerning the type of abdominal section-due to higher incidence of wound healing disorders-individual consideration should be made based on discussion with the mother and at least a single-shot antibiotic prophylaxis is necessary after cutting the umbilicus, which we applied [29]. Efficient thrombosis prophylaxis is recommended during the postoperative period and due to the higher incidence of subinvolution of uterus administration of uterotonic agent is recommended in the puerperal period [9].
Our patient suffered from combined (acquired) thrombophilia (extremely obese, pregnant, thrombophlebitis below the knee, then surgery, and postoperative immobilization). In case of such extreme bodyweight no any clinical experience or dosage recommendation for LMWH was available [17, $21,22,25,26]$. Heparin therapy has demonstrated to be efficient despite the route of administration other than the recommendations (upper arm SC instead of abdomen SC) and extreme obesity. This was confirmed by measurement of change in $\mathrm{fX}$ activation. In this rare bodyweight category treatment with Enoxaparin $2 \times 1$ to $1.5 \mathrm{mg} / \mathrm{kg}$ bw bid is the correct dosage.

\section{Established Facts}

Obese pregnant women have a significantly increased the risk of venous thromboembolic event; moreover, extremely obese people are categorized as "very high risk" patients. LMWH is recommended both for prophylaxis and treatment of thromboembolic diseases (recommendation level "2C"). In case of quite extreme bodyweight there is no dosage recommendation and clinical practice for LMWH.

\section{Novel Insights}

In this rare bodyweight category treatment with Enoxaparin $2 \times 1$ to $1.5 \mathrm{mg} / \mathrm{kg} \mathrm{bw}$ bid is the correct dosage. In case of extreme obesity the heparin therapy has demonstrated to be efficient despite the route of administration other than the recommendations (upper arm SC instead of abdomen $\mathrm{SC}$ ). This was confirmed by measurement of change in $\mathrm{fX}$ activation.

\section{Conflict of Interests}

The authors declare that they have no conflict of interests.

\section{Acknowledgment}

The study have been supported by the European Union (TÁMOP application). 


\section{References}

[1] Controlling the global obesity epidemic. WHO health topics, 2004.

[2] P. Foy and S. Moll, "Thrombophilia: 2009 update," Current Treatment Options in Cardiovascular Medicine, vol. 11, no. 2, pp. 114-128, 2009.

[3] R. Michlin, M. Oettinger, M. Odeh et al., "Maternal obesity and pregnancy outcome," Israel Medical Association Journal, vol. 2, no. 1, pp. 10-13, 2000.

[4] A. S. Kumari, "Pregnancy outcome in women with morbid obesity," International Journal of Gynecology and Obstetrics, vol. 73, no. 2, pp. 101-107, 2001.

[5] P. M. Catalano, "Obesity, insulin resistance, and pregnancy outcome," Reproduction, vol. 140, no. 3, pp. 365-371, 2010.

[6] P. M. Catalano, "Management of obesity in gregnancy," Obstetrics and Gynecology, vol. 109, pp. 419-433, 2007.

[7] A. Mantakas and T. Farrell, "The influence of increasing BMI in nulliparous women on pregnancy outcome," European Journal of Obstetrics Gynecology and Reproductive Biology, vol. 153, no. 1, pp. 43-46, 2010.

[8] G. A. Davies, C. Maxwell, L. McLeod et al., "Obesity in pregnancy," Journal of Obstetrics and Gynaecology Canada, vol. 32, no. 2, pp. 165-173, 2010.

[9] J. M. Baeten, E. A. Bukusi, and M. Lambe, "Pregnancy complications and outcomes among overweight and obese nulliparous women," American Journal of Public Health, vol. 91, no. 3, pp. 436-440, 2001.

[10] A. T. Bianco, S. W. Smilen, Y. Davis, S. Lopez, R. Lapinski, and C. J. Lockwood, "Pregnancy outcome and weight gain recommendations for the morbidly obese woman," Obstetrics and Gynecology, vol. 91, no. 1, pp. 97-102, 1998.

[11] L. C. Castro and R. L. Avina, "Maternal obesity and pregnancy outcomes," Current Opinion in Obstetrics and Gynecology, vol. 14, no. 6, pp. 601-606, 2002.

[12] T. Gross, R. J. Sokol, and K. C. King, "Obesity in pregnancy: risks and outcome," Obstetrics and Gynecology, vol. 56, no. 4, pp. 446-450, 1980.

[13] M. C. Mitchell and E. Lerner, "A comparison of pregnancy outcome in overweight and normal weight women," Journal of the American College of Nutrition, vol. 8, no. 6, pp. 617-624, 1989.

[14] R. L. Goldenberg, "Prepregnancy weight and pregnancy outcome," JAMA, vol. 275, no. 14, pp. 1127-1128, 1996.

[15] L. K. Callaway, J. B. Prins, A. M. Chang, and H. D. McIntyre, "The prevalence and impact of overweight and obesity in an Australian obstetrics population," Medical Journal of Australia, vol. 184, no. 2, pp. 56-59, 2006.

[16] H. K. Satpathy, A. Fleming, D. Frey, M. Barsoom, C. Satpathy, and J. Khandalavala, "Maternal obesity and pregnancy," Postgraduate Medicine, vol. 120, no. 3, pp. 1-9, 2008.

[17] R. M. Bauersachs, J. Dudenhausen, A. Faridi et al., "Risk stratification and heparin prophylaxis to prevent venous thromboembolism in pregnant women," Thrombosis and Haemostasis, vol. 98, no. 6, pp. 1237-1245, 2007.

[18] I. Pabinger and H. Grafenhofer, "Pregnancy-associated thrombosis," Wiener Klinische Wochenschrift, vol. 115, no. 13-14, pp. 482-484, 2003.

[19] W. H. Geerts, D. Bergqvist, G. F. Pineo et al., "Prevention of venous thromboembolism: American College of Chest Physicians evidence-based clinical practice guidelines (8th edition)," Chest, vol. 133, no. 6, pp. 381-453, 2008.
[20] P. Nathan, L. Clark, T. Delate, D. M. Witt, S. Parker, and R. McDuffie, "Anticoagulant medications in pregnancy: a retrospective evaluation in a health maintenance organization," Journal of Thrombosis and Thrombolysis, vol. 25, pp. 126-129, 2008.

[21] N. S. Fox, S. K. Laughon, S. D. Bender, D. H. Saltzman, and A. Rebarber, "Anti-factor xa plasma levels in pregnant women receiving low molecular weight heparin thromboprophylaxis," Obstetrics and Gynecology, vol. 112, no. 4, pp. 884-889, 2008.

[22] E. Friedrich and A. B. Hameed, "Fluctuations in anti-factor Xa levels with therapeutic enoxaparin anticoagulation in pregnancy," Journal of Perinatology, vol. 30, no. 4, pp. 253-257, 2010.

[23] J. Q. Wang, X. B. Shi, J. G. Yang, and D. Y. Hu, "In vitro anticoagulation monitoring of low-molecular-weight heparin," Chinese Medical Journal, vol. 122, no. 10, pp. 1199-1202, 2009.

[24] I. Pabinger and A. Greinacher, "Anti-factor Xa plasma levels in pregnant women receiving low molecular weight heparin thromboprophylaxis," Obstetrics and Gynecology, vol. 113, no. 3, pp. 740-741, 2009.

[25] G. H. Guyatt, D. J. Cook, R. Jaeschke, S. G. Pauker, and H. J. Schünemann, "Grades of recommendation for antithrombotic agents: American College of Chest Physicians evidence-based clinical practice guidelines (8th edition)," Chest, vol. 133, no. 6, pp. 123-131, 2008.

[26] J. Hirsh, Guidlines for Antithrombic Therapy, BC Dekker, Hamilton, Canada, 8th edition, 2008.

[27] J. Hirsh, K. A. Bauer, M. B. Donati, M. Gould, M. M. Samama, and J. I. Weitz, "Parenteral anticoagulants: American College of Chest Physicians evidence-based clinical practice guidelines (8th edition)," Chest, vol. 133, no. 6, pp. 141-159, 2008.

[28] D. S. Weitz and J. I. Weitz, "UPdate on heparin: what do we need to know?" Journal of Thrombosis and Thrombolysis, vol. 29, no. 2, pp. 199-207, 2010.

[29] M. Laville, M. Romon, G. Chavrier et al., "Recommendations regarding obesity surgery," Obesity Surgery, vol. 15, no. 10, pp. 1476-1480, 2005. 


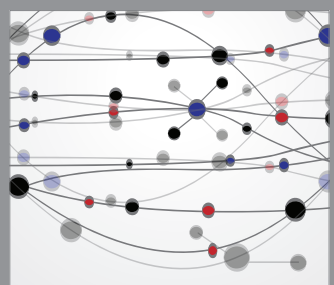

The Scientific World Journal
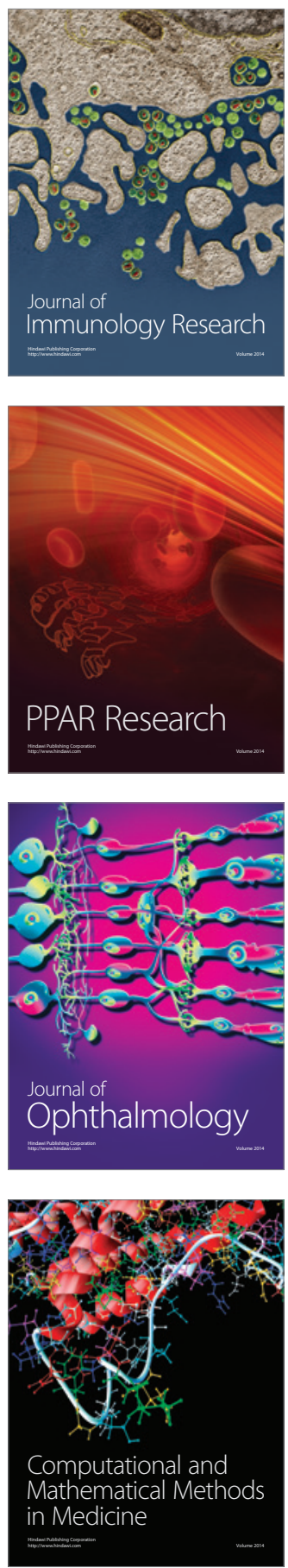

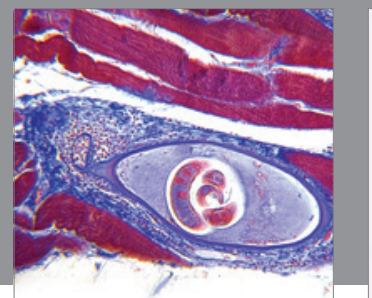

Gastroenterology

Research and Practice
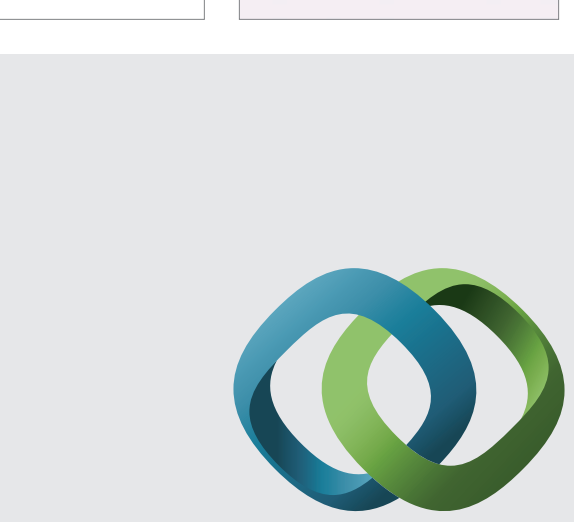

\section{Hindawi}

Submit your manuscripts at

http://www.hindawi.com
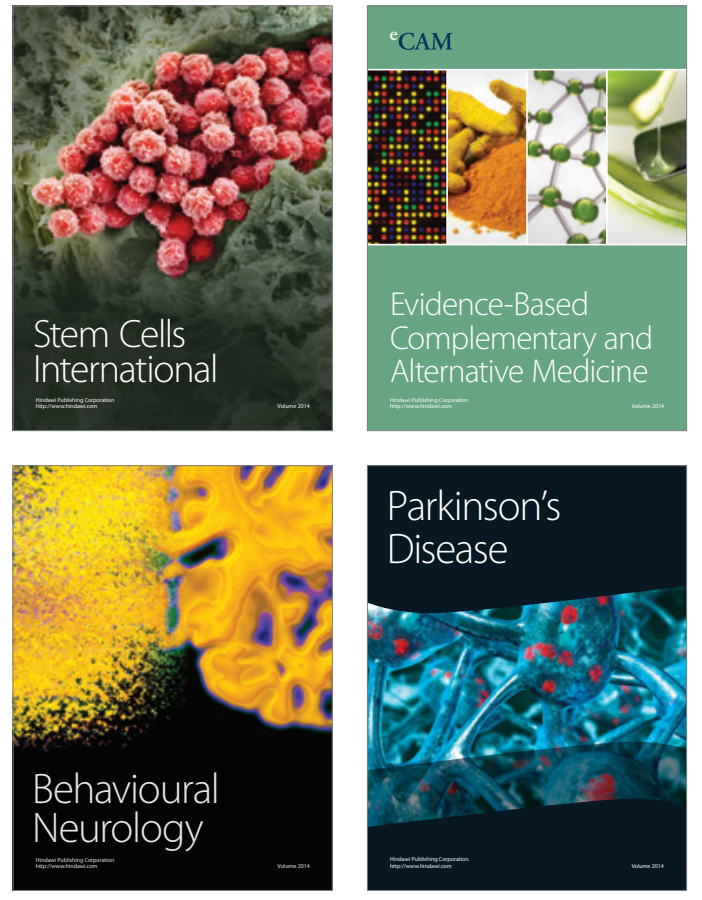
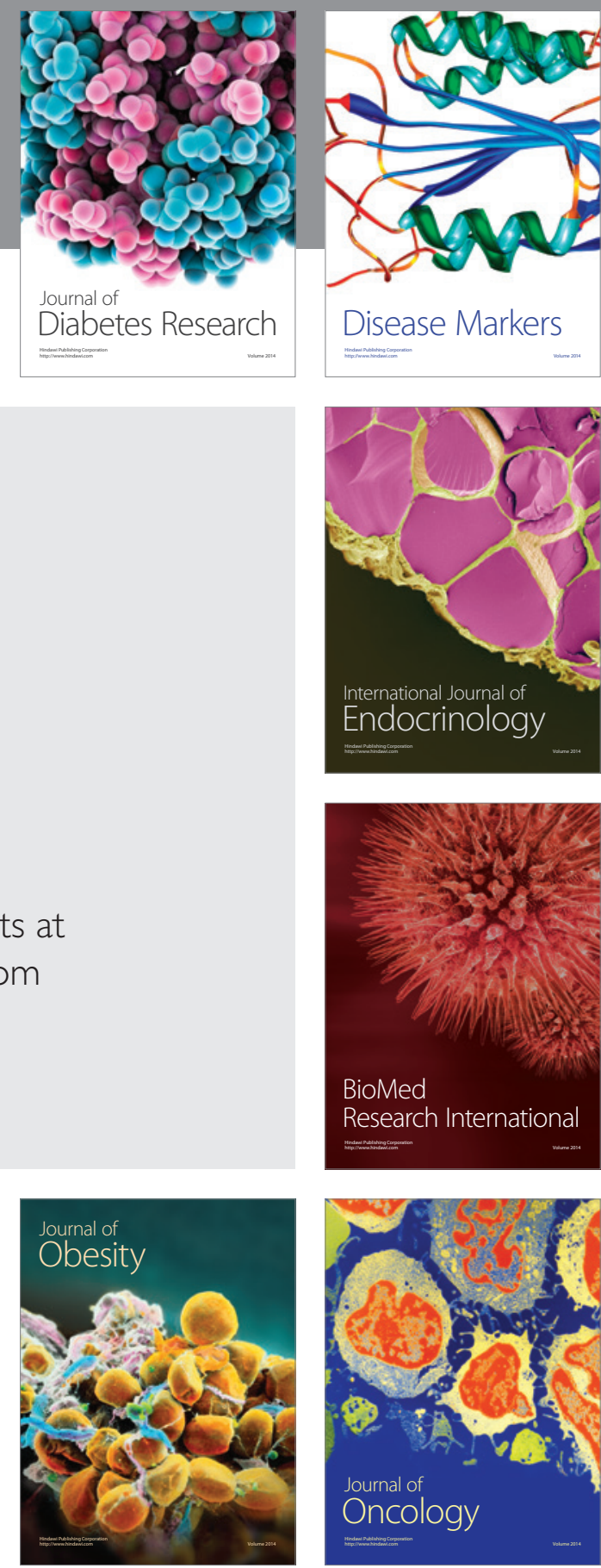

Disease Markers
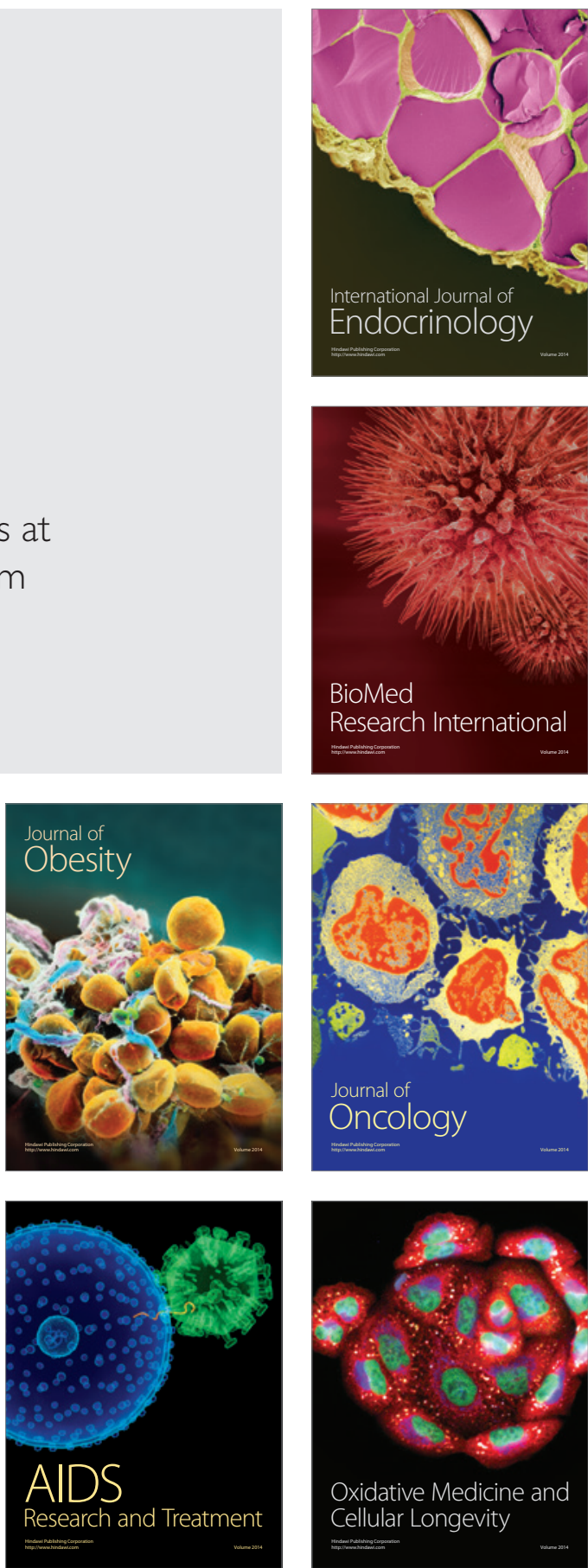